\title{
Die gestalte van die diaken na 125 jaar*
}

Prof. B. Spoelstra

\section{TOE DIAKENS NOG DIAKENS WAS}

Dit is ' $n$ voorreg om na 125 jaar juis op Rustenburg die geskiedenis van die diakendiens in oënskou te neem. Ek wil u net eers voorstel aan die eerste en oudste diaken in Suidelike Afrika.

Met die koms van ds. Johan van Arckel in 1665 is ook die eerste diaken Jan Reinier-zoon daargestel. Volgens gereformeerde gebruik moes hy ook by bevestiging die Formuliere van Eenheid onderteken. Blykbaar kon Jan nie sy naam teken nie en verskyn onder aan die bladsy twee kruisies met die byskrif: "Dit is het mercq van Jan Reinierzn". Nietemin was een van die eerste opdragte van die kerkraad dat die diaken aan die dominee 100 gulde moes voorsien om heimlik uit te deel waar hy nooddruf teegekom het.

Die Politieke Raad het die diakens uit 'n dubbelgetal benoem. Juis die VOC het by die werk van die diaken belang gehad, omdat hulle werk van destyds soos welsynsdiens, onderwysadministrasie, openbare werke en nog meer vandag by 'n paar staatsdepartemente tuishoort. Die diakens het die skool in Kaapstad vir arm kinders en slawe versorg. Wanneer kinders se ouers hulle ontval het, moes die diakens hulle by ander gesinne tuisbring, maar die diakens moes op hulle skoolbesoek bly let. Een van die diakens was skriba en akteversorger van die kerkraad. 'n Diaken-kassier het alle inkomste geadministreer en kwitansies uitgereik. ' $n$ Ander was die onderkerkmeester wat oor reparasies aan skoolen kerkgeboue toesig gehou het en kerkhuise aan behoeftiges verhuur het. Verder moes diakens behoeftiges versorg met klere, lewensonderhoud, doodkiste en begrafnisse. Hulle het die begraafplaas beheer. Die diakens was selfs verantwoordelik vir die 'brandspuit' (brandweer) in Kaapstad!

Die diakens het tydens die erediens weerskante van die preekstoel stelling ingeneem sodra die VDM die verdeling van sy preek aangekondig het. Elkeen het 'n lang stok gehad aan die punt waarvan 'n fluweelsakkie gehang het. Onderaan die sakkie was 'n tossel en 'n klokkie. Nadat die gemeente tot liefdadigheid aangespoor was, het die diakens rondgegaan om die liefdesgawes in te samel. Tydens die nagmaalviering het hulle by die tafels diens gedoen. (Moorrees 1937: 31, 66v, 71).

Die diaken in die voc-periode aan die Kaap was dus werklik onmisbaar en sy taak omvattend. Die Kerkorde van De Mist 1804 en die Engelse Administrasie in 1806 beêindig die intieme verhouding tussen die politieke en kerklike regeerders. Die staat het beheer oor die kerk en die skool, begraafplase, ens. oorgeneem. Die diens van die diakens is binne die gemeente teruggedring.

DIE DIAKEN IN DIE KERKRAAD 1859 - 1927

Toe die eerste Gereformeerde Kerk Rustenburg op 11 Februarie 1859 gestig is, het mense van Marico ds. Postma ook daarheen oorgenooi.

Voordrag tydens diakonale konferensie te Rustenburg op 1 September 1984. 
Die veldkornet van Marico, Jan Viljoen, was 'n baie sterk teenstander van die Gereformeerdes en het laat weet dat hy Postma se besoek met geweld sal verydel. Die diaken wat ds. Postma daarheen moes neem, het egter verseker dat indien hy nie die predikant in Marico sal besorg nie, is sy naam nie Gerrit Snyman nie! Dit was 'n tipiese taak van die diakens om predikante en ouderlinge op huisbesoek met kar-en-perde te vervoer. Hy moes die perde versorg maar het ook dikwels saam in huisbesoek gesit sonder om werklik daaraan deel te neem.

Die diakens is steeds by die 'kerkraad' gereken (vgl. art. $38 \mathrm{KO}$ ). In groot kerke was maar ongeveer agt wyke. Hulle was dus in die kerkraad tydens wyksverslae en besluite in sencura morum. Die ouderlinge het weer saam oor hulp in gevalle van nooddruf en behoefte besluit, trouens die ouderlinge het as ouer manne eintlik die besluite geneem vir die diakens om te gaan uitvoer wat besluit was. Armsorg en leniging van nood het dus meesal van die kerkraad uitgegaan met die diaken as die uitvoerder van besluite. Dit wek die gedagte dat die diaken 'n soort vakleerling was wat die ouderling na sy dienstyd, wat 'lewenslank' was, sou opvolg.

Die predikante is beroep en voorwaardes vasgestel nadat die ouderling en diaken hulle wyk saam deurreis het. Elke gesin het 'belofte' vir die 'traktement' gemaak in die vorm van kontant, perdevoer, vuurmaakhout, broodkoring, vleis, ens. Die predikant se beroepsbrief het dan ook traktement in die vorm van geld en goedere ingesluit. Dit was dan die taak van die diakens om die goedere volgens wyksbeurte te gaan insamel en by die pastorie af te dra.

Die diakens was in die vorige eeu ook intiem betrokke by die versorging van die Vrye Christelike Skole. Die diaken het sy amp kragtens sy plek in die kerkraad bedien. Dit was 'n groot onderskeiding vir 'n jong man om (soos die ou mense gesê het) 'kerkraad' te word of tot die 'swart span' toe te tree. Die diakendiens het voor 1927 in die sterk plattelandse patriargale opset, waar ouderdom gesag gesimboliseer het, nie 'n dinamiese selfstandigheid en roepingsgerigte gestalte vertoon nie. In terme van die 'kerk' was die diaken egter as 'helper' opvallend besig.

\section{DIE KRISIS RONDOM DIAKENDIENS 1927 - 1984}

Die diakenamp loop as gevolg van verskillende faktore gedurende die eerste kwart van hierdie eeu in 'n krisis vas.

Die sosiologie van die $19 \mathrm{e}$ eeu het die staat in die $20 \mathrm{e}$ eeu al meer verantwoordelik vir noodlenigingswerk gemaak. Ekonomiese faktore het na die oorloe van 1899 - 1902, 1914 - 1918, 1939 - 1945 en die resessies en depressies (veral in 1933) gereformeerde mense toenemend laat verstedelik Die kerke het die plattelandse ontvolking soos onbetrokke toeskouers bekyk (behalwe die Ned. Geref. Kerk se armsorg wat 'n magtige skema by Kakamas geloods het). Die stede het nuwe sosiale strukture, euwels, node en behoeftes opgetower. Die intieme, persoonlike en beskutte plattelandse leefwyse waar ek by Oom Piet kon gaan geld leen omdat hy my $\mathrm{Pa}$ en my familie so goed geken het, was iets van die verlede Vroeer het hierdie of daardie gesin 'n groep weeskinders met graagte in hulle huis geneem en aan hulle 'n toekoms probeer gee.

Teen 1930 was dit duidelik dat hierdie geborge milieu plek gemaak het vir onpersoonlike, gejaagde, geldgerigte, gemaksoekende stadspatroon. 


\section{In die Skriflig}

Ander kerke het met tehuise begin. Die idee het ook onder gerformeerdes posgevat.

Gepaard hiermee het die Doleansie in Nederland 1886 die gereformeerde teologie gestimuleer en onder andere besinning oor die 'ampte', ook besonderlik die diaken, gestimuleer. Die gedagtes het ook Suid-Afrika bereik en hier begin gis. Juis die kerkraad van Rustenburg, waar ons vandag vergader, vra die Sinode van 1924 om riglyne oor die diakendiens en wat dit inhou, te gee. Die Sinode van 1927 ontvang 'n meerderheidsen minderheidsrapport.

Die meerderheidsrapport bied ' $n$ indrukwekkende hoeveelheid Bybelgegewens en historiese feite om te bewys dat die diakendiens breër as blote armversorging gaan en ook die stoffilike belange van die kerk insluit. Hulle wil daarom diakens ook op meerdere vergaderings verteenwoordig hê. Die swak punt in hierdie betoog wat by die tradisionele Suid-Afrikaanse patroon aansluit, was dat nie meer soos die Skrif en kerkorde van ampsdifferensiasie kragtens gedifferensieerde roeping uitgegaan word nie, maar dat hulle die kerkraad in plaas van die dienste as vertrekpunt geneem het. Drie ampte in die kerkraad vereis die drie ampte in meerdere vergaderings.

Die minderheidsrapport het op spoor van die Bevestigingsformulier en Nederland die "tradisionele enger standpunt" (J. H. Coetzee 1953: 103) gegee.

Die diakonale taak is net armversorging maar die 'breë' kerkraad kon die kerkgoedere beheer. Hierdie rapport het sinodebesluit geword. Daarmee is ' $n$ proses ontketen wat die gestalte van die diaken aan die een kant positief en aan die ander kant negatief gevorm het.

\section{POSITIEWE VRUGTE VANAF 1927}

Die prinsipiële nadruk op die gedifferensieerde en eie taak van die diakens het daartoe gelei dat afsonderlike samekomste van die diakens (art. $40 \mathrm{KO}$ ) en beskikkingsreg van diakens oor 'diakonale fondse' (art. $25 \mathrm{KO}$ ) in die plaaslike kerke inslag en skering geword het.

Teen die diakonale konferensies soos hulle aanvanklik geopereer het en daarna die gesentraliseerde sinodalistiese oorname d.m.v. 'n burokrasie, kan kritiek ingebring word. Tog het die ontwikkeling van tehuise vir wese, onversorgde en gekommiteerde kinders en verskillende groepe van bejaardes uit die diakonale en kerklike bemoeienis na 1927 ontstaan. Daarmee is die veranderde sosiale omstandighede met ' $n$ aangepaste en gerigte diakonale diens ontmoet. Die diakens het in 'saamwerk' vanuit verskillende kerke roepingsbevrediging geput.

\section{NEGATIEWE VRUGTE VANAF 1927}

Die saamtrek in en besinning oor die diakenamp in sogenaamde diakonale konferensies na 1927 het die diaken-amp so sterk uitgelig dat die diakens eintlik 'n onafhanklike kerklike kategorie geword het. Dit was nie die gelowiges, die mense wat die kerk is, wat barmhartigheidswerk deur middel van die Godgegewe diakens gedoen het nie. Al die aandag is op die diakens gevestig. Dit het die diakens geword wat diakonale inrigtings deur middel van diakonale konferensies met diakonale fondse saam met of o.l.v. sinodale diakonale deputate daarstel, beheer en monopoliseer. Die onnodige en ongelukkige spanning tussen die Gereformeerde Stigting en die Sinodale Deputate vir Diakonale Inrigtings illus- 
treer hoe eksklusief die ontwikkeling was. Die diakens is as 't ware as 'n entiteit in sinodale deputateverband gelanseer, wat soos 'n satelliet buite die gemeente wentel, behalwe sporadiese 'plaaslike' hulpverlening. Hiermee saam het die owerheid d.m.v. die Departement Volkswelsyn sosiale versorging van bejaardes, ongeskiktes e.a. oorgeneem. Na die oorlog van 1939 - 1945 het ' $n$ industriële rewolusie en onderwys in SuidAfrika feitlik armoede in ons blanke kerke uitgewis. As die diakonale diens slegs op armversorging neerkom, het die diakens oorbodig en werkloos geraak. So aktief̂ en belade soos 'n diaken in die $17 \mathrm{e}$ eeu aan die Kaap was, so leeg en hol het sy plek in baie plaaslike kerke geword. Tegelykertyd het die feit dat die oppermagtige kerkraad i.p.v. dat eiesoortige gedifferensieerde dienste van opsieners en diakens as uitgangspunte geneem is, die diakens deur gewoonte en tradisie gekniehalter. Die diakens kon nie uitgaan en werk soek nie. Indien hulle inisiatief neem, is hulle maklik oor die vingers getik met "dit is nie julle taak nie" " dit is nie binne die plaaslike kerk nie", "dit is nie van die sinodale deputate nie", ens. Die maklikste manier om nie 'n fout te maak nie en om nie in gedrang te kom nie, was om niks te doen nie behalwe om insidenteel 'n arme te versorg en verder op omsendbriewe van sinodale deputate te reageer.

Die verhouding van die diaken tot die plaaslike kerk gee m.i. vandag rede tot kommer. Die prentjie lyk op die oog af asof die gemeente net die finansiele bron vir die diakonie is, min of meer soos die mense op straat dit vir die instansie by 'n straatkollekte is. Die werk van die diakens is nie die werk van die kerk nie. Die mense weet nie waarvoor hulle gee nie en ook nie waarom hulle moet gee nie. Hulle 'offer' nie. Die diakensdiens is meganies, gewoonte.

Die meeste diakens en diakoniee opereer op 'n wyse waarop die gelowige 'n stereotipe 'kollekte' in die erediens 'aan die diakens' afdra. Van 'barmhartigheid' of innig jammer kry (Luk $10: 33$ ) ervaar die gelowige niks en nòg die diakens nòg die predikant doen iets om die harte van die gemeente by die 'kollekte' vir konkrete nood te ontsluit. Die kerkmens weet nie vir wie hy gee of watter nood hy lenig nie. Die vroutjie wat hom Saterdag op die sypaadjie met 'n banier en bussie storm en 'n kaartjie aan hom speld, gryp hom as mens baie meer in sy hart as die diaken aan wie Christus die barmhartigheidswerk in sy kerk toevertrou het. Hierdie feit staan in skril kontras met die feit dat daar naby en ver aan elke kerk met diakens swart gereformeerdes is wat honger, arm, naak, sonder onderwys, sonder werk, in gebroke huise, verwaarloos sit. Hoe kan die diakens hier Christus nie preek nie!

Spesialisasie op die minimum aantal 'eie kerklike' projekte het die diakens verydel. Ek sề 'verydel', omdat ek glo dat die vermoè om te erbarm daar is - maar die patroon het vasgeroes en maak dit vir hulle onmoontlik om in 'barmhartigheid' te ontbrand. Diakens het vir my gesê dat hulle hulle diens met groot frustrasie verrig omdat hulle waarvoor hulle voor die Here by bevestiging 'ja' sê, in die praktyk nie raakloop nie. Hulle moet berus in 'n blote kerklike funksionaliteit wat grootliks in eindelose breë kerkraadsvergaderings opgaan.

Die gestalte van die diaken na 125 jaar toon dat hy ook niks gedoen het om die 'diakonie' in jong kerke te ontwikkel nie. In die meeste jong kerke is prakties geen diakonie en nog minder diakonale aktiwiteit, alhoewel 


\section{In die Skriflig}

nood ten hemel roep. Skynbaar glo sendende kerke dat Woordverkondiging en evangelisering sonder die daadprediking van diakens kan geskied (vgl. Jak 2). Laat ons onthou wat Jesus in Matt $25: 31$ - 46 oor die laaste oordeel sê.

Aan die ander kant mag dit wees dat ons in hierdie materialistiese tegniese eeu diakens kry wat dink geld hef nood op. Hulle gee geld hiervoor en daarvoor. Stoflike gawes sonder die woord van evangelie is egter vrugteloos en dood. Diakendiens moet Woorddiens wees wat Christus deur middel van stoflike gawes by die behoeftige bedien. Binne die Christian Reformed Church van die vSA lê 0.a. Eugene Rubridge nadruk op die onskeibare eenheid tussen daad en Woord in die diakonale diens.

\section{DIAKENS EN KERKEVERGADERINGS}

Voor 1927 het die diakens as 'hulp-ouderlinge' net soos die ouderlinge kerke in die kerkevergaderings verteenwoordig. Tog het die sake wat as 'diakonaal' in 1927 gedefinieer is nie eers in klassikale verband aandag geniet nie. Indien dit sou gebeur het, sou die predikante en ouderlinge in die klassis tog maar die besluite geneem het. Teen hierdie agtergrond bevredig die oplossing in die Geref. Kerk Nederland om diakens vir sekere agendapunte na die klassis af te vaardig. glad nie. Dit word deur vergaderingstrukture en nie deur die gedifferensieerde ampsroeping bepaal nie.

Die Kerkorde en Bevestigingsformulier stel die beginsel vir die plaaslike kerk en dieselfde beginsel moet $m$.i. deugetrek word na die klassis. Indien daar verder gemeenskaplike werk tussen kerke in wyer verband bestaan, kan dit ook verder deurgetrek word. Die diakens kom in die plaaslike kerk saam vir hulle dienswerk, maar kragtens die een kerk van Christus waaroor die ouderlinge toesig hou, doen die diakens in die kerkraad verslag van hulle werk. Die ouderlingtoesig berus nie op die waardigheid van die ouderlingsamp of die struktuur van die kerkraad nie, maar op die gedifferensieerde roeping van die ouderlinge om alles in die kerk te meet aan die Woord van die Hoof van die kerk.

Wanneer die diakens met gemeenskaplike terreine tussen kerke te doen $\mathrm{kry}$, is dit logies dat die kerke (gemeentes) deur middel van diakens met mekaar kommunikeer en handel oor sake waartoe die Here diakens geroep het. Ons kan so 'n samekoms 'n 'streeksdiakonale samekoms' of wat ook al noem. Tegelykertyd vereis die roeping wat op die ouderling gelê is weer dat die diakens van hulle handelinge weer in die klassis verslag moet doen. Hierdie gedagte is deur die Sinode van 1976 afgewys op gronde wat nie van die roepingsbepaalde dienste (art. $2 \mathrm{KO}$ ) nie, maar van die vergaderingstruktuur en 'n eksklusiewe vertolking van 'regeeramp' uitgegaan het. Diakens is tog geroep om hulle eie huis te regeer. Ek glo wanneer diakens oor sake waartoe die Here hulle geroep het met mekaar saam vergader en handel sal 'Streeksdiakonieè' vanseif na vore kom. Dit moet egter op konkrete diakonale aktiwiteite in naburige kerkverband gerig wees en die toesig deur die ouderlinge met die Woord oor hulle kerklike handeling erken.

Die problematiek rondom die diaken en die vraag of sy diens werklik so eng soos deur die Sinode 1972 beperk mag word, het in die kerke van die Westelike Klassis tot vrae gelei, waardeur die Sinode van 1982 uiteindelik opening vir ' $n$ breër ontplooiing van die diakendiens gegee het. 


\section{DIE GESTALTE VAN DIE DI $/$ KEN VANDAG}

$\mathrm{Na} 125$ jaar staan die diaken aan die een kant duideliker in 'n gedifferensieerde en 'n gespesifiseerde diens binne die plaaslike kerk. Aan die ander kant het die diaken in die 125 jaar los van die kerk (gemeente) geraak en t.o.v. barmhartigheidsdiens die gemeente grootliks verplaas in plaas van in hierdie taak ontplooi. Dit is asof die 'diakens' en 'diakenkas' en 'diakenwerk' nie deel van die kerk is nie. Die gemeente offer en bid daarom ook nie danig vir diakenwerk nie. Die diakens kan gevolglik ook maar jong en onervare manne wees. Die werk is ook nie van so 'n aard dat ' $n$ nuut bevestigde diaken eers ingelig en toegerus moet word vir wat hy moet doen nie. Selfs al sou diakenwerk net barmhartigheidsdiens wees, moet $u$ uself afvra hoeveel preke $u$ al gehoor het waarin die dominee met nadruk die lig van die Woord op die roeping laat val het? Dr. J. A. Schutte dwing met sy boekie Want Ek het honger gehad en julle het My nie te ete gegee nie rekenskap af oor die diakonale bewoènheid in ons tyd waarin die Marxisme juis beloof om die wêreld van armoede te verlos en ware mens-wees moontlik te maak. Volgens $\mathrm{dr}$. Schutte is die 'Burial Societies' vir swart mense dikwels meer by hulle lewe betrokke ( soos die eerste diakens aan die Kaap?) as die kerk. Juis die diakens moet die evangelie in die taal van vandag vertaal. Die diakens kan hulleself verryk deur telkens 'n kwartier van 'n diakenvergadering aan een van die kort hoofstukke van die boekie van $\mathrm{dr}$. Schutte te bestee. Die diakens moet relevant in ons tyd word.

HOE KAN DIE DIAKEN HOM SPIEEL?

Die Here Jesus het net een kerk, die gelowiges aan wie Hy 'n nuwe lewe gee. Daardie kerk word sigbaar in die geloof en werk van mense in 'n plaaslike kerk. Hy het daarom dienste gegee om die geloof en werk te ontplooi tot eer van God en heil van mense. Daarvoor moet die diakens waarlik diakens wees.

\section{Doelwitte en beplanning}

Die diakens moet gereeld, minstens een maal per jaar kort- en langtermyn doelwitte stel. Op die korttermyn kan 'n bepaalde projek, byvoorbeeld hulp in 'n vloedramp of vir slagoffers van die droogte-ramp in 1983 gestel word. Het die diakens ons kerkmense die droogtenood van ander wat daarin ondergegaan het, laat voel? Het die diakens selfstandig vir hulle hierin 'n doelwit gestel of wag hulle op deputate om inisiatief te neem? Langtermyn beplanning kan bv. op tehuise, die jong kerke en asseblief tog op meer as een taak gerig wees! Wat van beplande weerstand met daad en Woord teen die oprukkende Marxisme?

\section{Betrokkenheid}

Die Here Christus het die diakens met die oog op sy gemeente gegee en geroep om die gemeente te lei en aan te spoor tot werke wat liefde vergestalt. Hulle moet dus betrokke wees by wat God in Christus in die wêreld doen. Volgens Matt 25 is dit juis wat die gelowiges (dissipels) aan mense wat honger en dors ly, doen wat toon of die gelowiges vir Christus omgee. Betrokke-wees by die nood van ander is Christen-wees, sê Matt 25. Is die diakens werklik so betrokke dat hulle die gemeente tot liefde en goeie werke aanspoor - of is hulle met roetinekollektes tevrede wat hulle min of meer soos 'n maatskappy se direksie sy winste laat verdeel? 


\section{In die Skriflig}

\section{Motivering}

Motivering hang nou saam met die doelwit wat 'n mens wil bereik. Die wêrelddiakonaat van die Wêreldraad van Kerke word byvoorbeeld duidelik deur mede-menslike oogmerke gemotiveer. Elke diaken moet weet wat hom en sy mede-diakens motiveer om nog vandag hierdie 'roeping' te aanvaar. Die diakonale patroon moet die geleentheid bied om God te verheerlik en in naam van Christus deur die gemeente nood te lenig - anders moet frustrasie intree.

\section{Verkenning}

Elke diaken moet voortdurend die geleenthede verken wat vandag roep om Christus met die daad te verkondig. Elke diaken moet in gesprek met sy tyd en omgewing verkeer en van oomblik tot oomblik die prioriteite waartoe God ons roep, vasstel.

\section{Toerusting}

Die taak moet vanself om toerusting roep. Indien toerusting nie nodig is nie, is die vraag of daar werklik 'n diens verrig word.

\section{Solidariteit}

Die taak van die diaken is omvattend, gevarieerd omdat dit die gemeente omspan. In plaas van dat die diakens ander uitsluit moet hulle byvoorbeeld jong mense, vroue of pensioenarisse vir hierdie of daardie werk mobiliseer en met hulle saamneem. Die diakens mag nie die taak wat die Here vir elke gelowige gegee het vir die diaken 'in sy amp' monopoliseer nie. Die kerk moet leef in wat mense met woorde en dade doen, anders skop 'n sterwende kerk nog net flouweg in die enkele takies wat die diakens op 'n diakonale vergadering gou-gou in 'n halfuur afhandel.

\section{Evaluering}

Elke diaken behoort voortdurend sy diens en dié van sy mede-diakens te evalueer onder besef dat hierdie werk vir die Here en nie vir die kerk gedoen word nie (vgl. art. $81 \mathrm{Ko}$ ). Die diakens moet ook terugvoering kry van die plekke waar hulle gewerk het en die inligting aan die kerk deurgee.

8. Jy, diaken

Die Bybel laat die diaken hand in eie boesem steek om te vra in hoeverre die liefde van God my persoonlik dryf om aan ander te doen wat ek gedurig bid dat God in sy groot barmhartigheid aan my moet doen. Juis die diakens kan 'n gemeente so lei dat geen magtelose skuldgevoel die lewe verdof nie. Geen strukture, voorskrifte of gewoontes mag die gemeente onder leiding van die diakens lamlê, sodat Satan vandag met ' $n$ valse evangelie van kommunisme aan die wêreld skynverlossing belowe nie.

Kortom, broeders diakens, neem die gemeente met u saam op 'n pad van liefde wat in dade ooplê: "Laat julle lig so voor die mense skyn, dat hulle julle goeie werke kan sien en julle Vader wat in die hemel is, verheerlik."

\section{VERWYSINGS}

Coetzee, J.H. 1953: Die barmhartigheidsdiens van die Gereformeerde Kerk in SuidAfrika (1859 - 1949). Potchefstroom: Pro Rege Pers.

Moorrees, A. 1937: Die Nederduitse Gereformeerde Kerk in Suid-Afrika 1652 - 1873. Kaapstad: SA Bybelvereniging.

Schutte, J.A. 1975. Want Ek het honger gehad en julle het $M y$ nie te ete gegee nie.

Potchefstroom: Pro Rege Pers 